\title{
Pulmonary arterial hypertension associated with neurofibromatosis type 1
}

\author{
Miguel F Carrascosa, ${ }^{1}$ Isabel Celemûn Larroque, ${ }^{2}$ Juan-Luis Garcûa Rivero, ${ }^{3}$ \\ José-Antonio Saiz-Quevedo Garcûa, ${ }^{1}$ Marta Cano Hoz, ${ }^{1}$ Miguel Ares Ares, ${ }^{2}$ Xabier Arrastio López, ${ }^{2}$ \\ José-Ramón Salcines Caviedes ${ }^{4}$
}

${ }^{1}$ Department of Internal Medicine, Hospital of Laredo, Laredo, Spain

${ }^{2}$ Cardiology Section, Hospital of Laredo, Laredo, Spain

${ }^{3}$ Respiratory Medicine Section, Hospital of Laredo, Laredo, Spain

${ }^{4}$ Digestive Diseases Section, Hospital of Laredo, Laredo, Spain

Correspondence to Miguel F Carrascosa, mcarrascosa@hlrd.scsalud.es

\begin{abstract}
Summary
The authors report a case of severe pulmonary arterial hypertension (PAH) in a 75-year-old woman who had received a diagnosis of neurofibromatosis type 1 (NF1) 23 years before. She presented with progressive dyspnoea and recurrent syncope. Even though the patient initially improved after starting supportive and specific treatment for $\mathrm{PAH}$, she then deteriorated and died from respiratory failure 11 months after the diagnosis of PAH. Prompt recognition of such an unusual association between PAH and NF1 and appropriate therapeutic intervention could ameliorate quality of life and prolong survival in this patient population.
\end{abstract}

\section{BACKGROUND}

Neurofibromatosis type 1 (NF1) is a quite common disorder affecting approximately 1 in 3500-5000 people worldwide. ${ }^{1-3}$ Although infrequent, arterial vasculopathies are well-recognised complications of this disease and one of the most important causes of early death in persons with NF1. ${ }^{4}$ Pulmonary arterial hypertension (PAH) in patients with NF1 has also been described ${ }^{2-10}$ and is thought to be secondary to an underlying vasculopathy. ${ }^{2}$ In fact, at the recent 4th World Symposium on Pulmonary Hypertension, NF1 was accepted as an additional cause of PAH. ${ }^{11}$ Although the present report does not provide unique information, we consider it may be of interest for a wide range of clinicians because it deals with a condition that they could find in their customary practice: a NF1 patient with dyspnoea and/ or syncope. Increased awareness of such a possible association between PAH and NF1 may help early identification and improvement in cases similar to ours.

\section{CASE PRESENTATION}

A75-year-old womanwas admitted in ourlocal hospital with a 9-month history of progressive exertional dyspnoea that had worsened over the preceding 3 weeks. She also had suffered from recurrent syncope in the last 5 months. Her medical history included NF1, idiopathic hypertension, osteoporosis, hiatal hernia and chronic, non-specific, elevation of $\gamma$-glutamyl transpeptidase-thought to be druginduced. She was taking omeprazole, losartan, furosemide, alendronate, calcium and vitamin D. The patient denied toxic exposures or use of alcohol, tobacco, appetite suppressant or illicit drugs. There was no previous history of fetal loss, thrombophlebitis, arterial thrombosis, pulmonary embolism, chronic haemolytic anaemia or splenectomy. She denied any signs or symptoms suggestive of connective tissue disease, vasculitis, obstructive sleep apnoea or liver disease. Lastly, our patient had always lived near to the beach.

\section{INVESTIGATIONS}

On admission, she was apyrexial, her blood pressure was 99/52 $\mathrm{mm} \mathrm{Hg}$, pulse $84 \mathrm{bpm}$ and respiratory rate 28 breaths per min. She had multiple both cutaneous neurofibromas and café-au-lait macules (figure 1) and freckling in the axillary and inguinal regions. Physical examination was otherwise remarkable for dorsal kyphosis, increased jugular venous pressure, a systolic murmur along the lower left sternal margin and peripheral oedema. $\mathrm{PaO}_{2}$ was $57 \mathrm{~mm} \mathrm{Hg}$, $\mathrm{PaCO}_{2} 20 \mathrm{~mm} \mathrm{Hg}$ and $\mathrm{pH} 7.48$ while breathing room air. Relevant blood test results were white cell count $13.9 \times 10^{9} / 1$ (neutrophils $11.9 \times 10^{9} / 1$ ), normal platelet count, D-dimer $1.39 \mu \mathrm{g} / \mathrm{ml}$ (normal <0.5), $\gamma$-glutamyl transpeptidase 161 IU/1 (<39) and alkaline phosphatase 137 IU/l (<104). Renal function and coagulation tests gave normal results. Serology for HIV and hepatitis B and C virus was negative. Antinuclear and antineutrophilic cytoplasmic antibodies were undetectable and serum level of rheumatoid factor was normal. Echocardiography revealed severe dilatation of the right chambers, right ventricle systolic dysfunction and severe functional tricuspid regurgitation (tricuspid regurgitant jet velocity $\left.\left(\mathrm{V}_{\mathrm{TR}}\right), 4.8 \mathrm{~m} / \mathrm{s}\right)$. Other remarkable echocardiographic findings were normal left ventricular (LV) both systolic function and wall thickness, reduction in LV cavity size, normal left atrium cavity, and absence of mitral, aortic valve, or interventricular or interatrial septum defects. There was no pericardial effusion. The inferior vena cava was dilated without respiratory changes. Estimated pulmonary artery systolic pressure $\left(\mathrm{PAP}_{\mathrm{s}}\right)$ was 112 $\mathrm{mm} \mathrm{Hg}$ (estimated $\mathrm{PAP}_{\mathrm{s}}=4\left(\mathrm{~V}_{\mathrm{TR}}\right) 2$ +estimated right atrial pressure; since inferior vena cava and hepatic veins were 


\section{BMJ Case Reports}

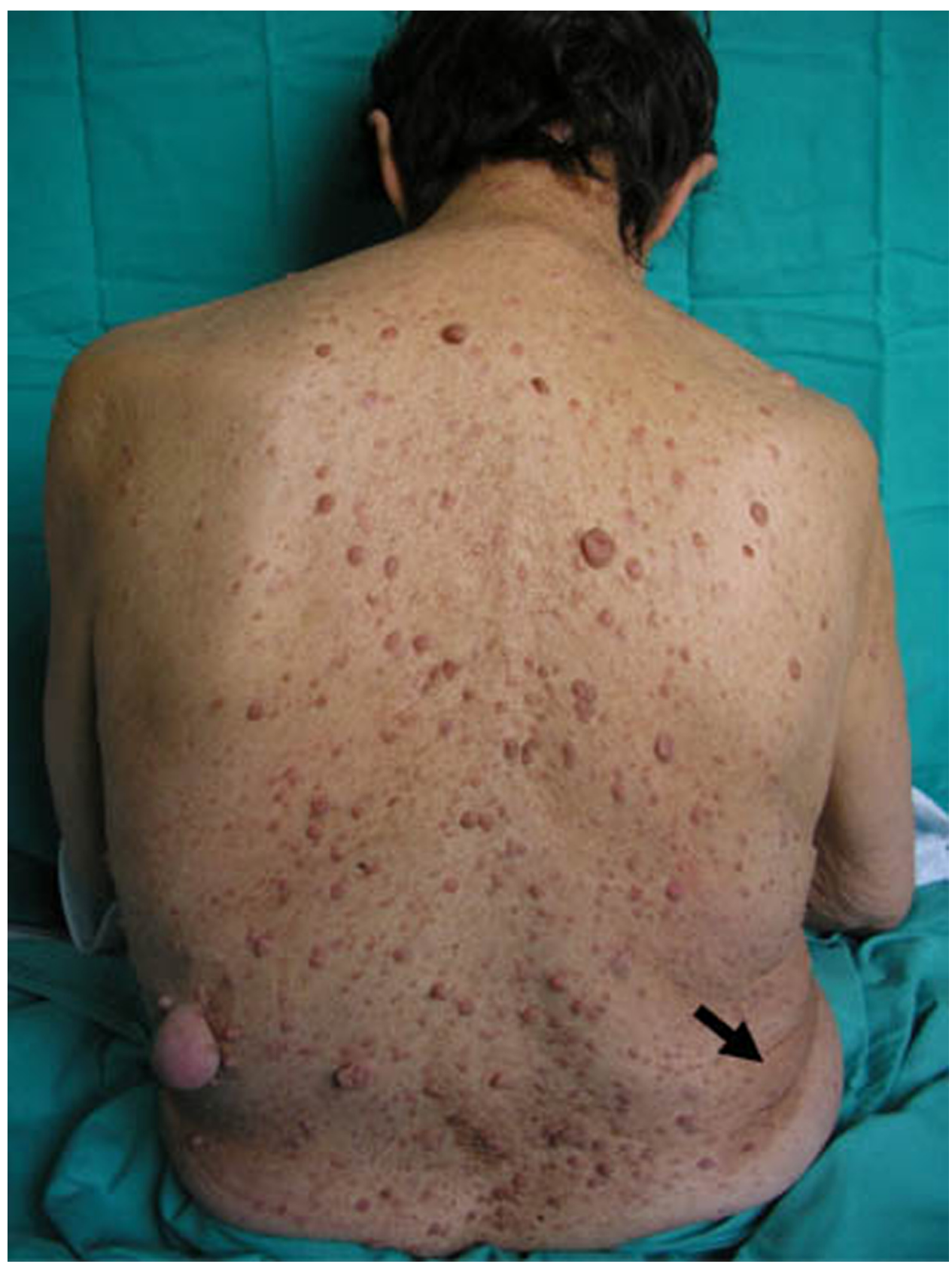

Figure 1 Patient with multiple cutaneous neurofibromas and café-au-lait macules (arrow points out to the main café-au-lait spot).

dilated, without respiratory changes, right atrial pressure was considered to be $20 \mathrm{~mm} \mathrm{Hg}^{12}$ ). The estimated mean pulmonary artery pressure $\left(\mathrm{PAP}_{\mathrm{m}}\right)$ was $70.32 \mathrm{~mm} \mathrm{Hg}$ $\left(\mathrm{PAP}_{\mathrm{m}}=0.61 \times \mathrm{PAP}_{\mathrm{s}}+2^{13}\right)$. Pulmonary function tests showed the following results: forced expiratory volume in $1 \mathrm{~s}\left(\mathrm{FEV}_{1}\right)$ 1.601 (95\% of predicted), forced vital capacity (FVC) 2.09 litres (86\%), FEV 1 /FVC 79.05 (110\%) and forced expiratory flow $25-75 \% 1.59$ litres (137\%). Thoracic CT disclosed neither signs of pulmonary embolism nor parenchymal or interstitial lung disease. A 6-min walk test was done but the patient finished early because of progressive dyspnoea (she walked only $170 \mathrm{~m}$ in $4 \mathrm{~min}$; arterial $\mathrm{O}_{2}$ saturation was $91 \%$ initial and $83 \%$ post-exercise). Finally, abdominal ultra- sonography was normal except for dilated suprahepatic veins. A diagnosis of very likely PAH related to NF1 was established. Haemodynamic study, to confirm PAH, was not carried out because she was deemed too frail; we cannot perform such a procedure in our centre and it was not regarded as essential for the patient management. Moreover, $\mathrm{V}_{\mathrm{TR}}$ and $\mathrm{PAP}_{\mathrm{s}}$ values seemed to be sufficiently increased to make a diagnosis of PAH with confidence. In addition, the rest of the available echocardiographic findings observed in the patient seemed militate against the presence of underlying pulmonary venous hypertension. As complementary information, she did not have evidence of vasculopathy outside the lungs. 


\section{TREATMENT}

Besides increasing the dose of furosemide and adding spironolactone, we started our patient on oxygen, oral anticoagulation and sildenafil ( $20 \mathrm{mg}$ every $8 \mathrm{~h}$ ).

\section{OUTCOME AND FOLLOW-UP}

Although symptoms and exercise tolerance improved initially she deteriorated over the next few months and died at home from respiratory failure in November 2008. No autopsy was performed.

\section{DISCUSSION}

NF1 is an autosomal dominant condition caused by heterozygous mutations of the NF1 gene, which is located on chromosome $17 .{ }^{4} \mathrm{NF} 1$ has approximately $100 \%$ penetrance and variable phenotypic expression with $50 \%$ of cases being sporadic. ${ }^{14}$ This disorder mainly involves the skin (café-au-lait macules, intertriginous freckling), peripheral nervous system (neurofibromas) and iris (Lisch nodules). ${ }^{34}$ Furthermore, NF1 patients may develop learning disabilities, central nervous system abnormalities, plexiform neurofibromas, gastrointestinal tumours and bony dysplasia. ${ }^{13}$ ${ }^{4}$ Our patient met the National Institutes of Health consensus criteria for the diagnosis of $N F 1^{15}$ because she had (1) more than six café-au-lait macules $>15 \mathrm{~mm}$ in greatest diameter, (2) multiple cutaneous neurofibromas and (3) axillary and inguinal freckling.

NF1 can also cause arterial vasculopathies but the frequency and pathogenesis of this serious complication of the disease remains not well-known. ${ }^{2}{ }^{4}{ }^{16}$ NF1 vasculopathy mainly involves the cerebral, renal, coronary and peripheral vascular beds ${ }^{4}{ }^{6}$ and may produce stenosis, occlusion, aneurysm, rupture or arteriovenous fistula formation. ${ }^{416}$ In addition to malignant peripheral nerve sheath tumours, vasculopathies are the most relevant causes of early death in NF1 individuals. ${ }^{4}$ Neurofibromin, the NF1 gen-encoded protein, has a role in both tumour suppression and regulation of cell growth and proliferation. ${ }^{3} 16$ Since neurofibromin is expressed in endothelial and smooth muscle cells of blood vessels, ${ }^{216}$ it has been hypothesised that its deficient function could originate a vasculopathy by impairing the response of these cells to growth suppressor signals. ${ }^{16}$

Pulmonary arteriopathy and secondary PAH have been recognised in NF1 patients and the long-term prognosis of such association is poor. ${ }^{2}$ To our knowledge, as of January 2010, this association (NF1-PAH) has been described in 12 patients $^{2}{ }^{5-10}$ (female/male ratio 9/3; mean age 53.8 y (16-72)). All patients suffered from gradually progressive dyspnoea. The presence of a pulmonary vasculopathy may be suspected on the basis of the mosaic pattern of lung attenuation seen on the chest CT or high resolution CT. The mosaic pattern is defined as sharply demarcated areas of heterogeneous attenuation in the pulmonary parenchyma and it can arise from cardiac, lung and vascular disease. ${ }^{2}$ Therefore, such radiological findings could not be considered as a specific or pathognomonic sign of pulmonary vasculopathy. The mosaic pattern has been observed in 4 of the 12 cases of NF1-associated PAH previously reported. In our patient, pulmonary vasculature appeared normal and mosaic pattern was not detected.

In the 12 previous cases, like in ours, extensive workup revealed no evidence of diseases or findings to explain PAH other than NF itself. Pathological study was performed in only three patients, ${ }^{29}$ which revealed increased intimal and medial thickness and plexiform (or angiomatoid) lesions in the pulmonary arterial bed.

The bone morphogenic protein receptor 2 (BMPR2) gene is mutated in $70 \%$ of patients with familial $\mathrm{PAH}$ and $20-25 \%$ of patients with idiopathic PAH. ${ }^{2}{ }^{17}$ BMPR2 gene analysis is very important to exclude a heritable or idiopathic PAH when the familial history of the patient is unsure. BMPR2 gene analysis has been performed in 5 of the 12 previous cases of NF1-associated PAH and no mutations or rearrangements were found in them. We did not perform BMPR2 gene testing in the present case but the patient had no familial history of PAH or NF1.

Despite the adverse outcome, some improvement in symptoms and pulmonary pressures can be achieved by both supportive and specific treatment for pulmonary hypertension-calcium channel blockers, endothelin receptor antagonists, prostanoids and phosphodiesterase type- 5 inhibitors. $^{2} 13$ 18-20 Therefore, when dealing with NF1 patients with progressive dyspnoea and/or syncope, clinicians should do not forget the possible presence of NF1associated PAH.

\section{Learning points}

NF1 is one of the most common inherited disorders. People with NF1 can develop a characteristic vasculopathy, which may affect vessels ranging in size from the proximal aorta to small arterioles.

- PAH has been described in NF1 patients and is thought to be caused by a NF1-related vasculopathy.

- NF1 patients with progressive dyspnoea and/or syncope should be investigated to rule out the presence of PAH. However, NF1-associated PAH is a diagnosis of exclusion and patients need proper workups to exclude secondary causes of $\mathrm{PAH}$.

- Patients with NF1 and PAH have a generally poor longterm prognosis but some improvement can be achieved using supportive and specific treatment.

\section{Competing interests None.}

Patient consent Obtained.

\section{REFERENCES}

1. Theos A, Korf BR. Pathophysiology of neurofibromatosis type 1. Ann Intern Med 2006;144:842-9.

2. Stewart DR, Cogan JD, Kramer MR, et al. Is pulmonary arterial hypertension in neurofibromatosis type 1 secondary to a plexogenic arteriopathy? Chest 2007;132:798-808.

3. Ferner RE. Neurofibromatosis 1 and neurofibromatosis 2: a twenty first century perspective. Lancet Neurol 2007:6:340-51.

4. Jett K, Friedman JM. Clinical and genetic aspects of neurofibromatosis 1. Gene t Med 2010;12:1-11

5. Porterfield JK, Pyeritz RE, Traill TA. Pulmonary hypertension and interstitial fibrosis in von Recklinghausen neurofibromatosis. Am J Med Genet 1986;25:531-5.

6. Samuels N, Berkman N, Milgalter E, et al. Pulmonary hypertension secondary to neurofibromatosis: intimal fibrosis versus thromboembolism. Thorax 1999;54:858-9.

7. Aoki Y, Kodama M, Mezaki T, et al. von Recklinghausen disease complicated by pulmonary hypertension. Chest 2001;119:1606-8.

8. Hernández FJG, Román JS, Medina CO, et al. Primary pulmonary hypertension in a patient with neurofibromatosis. Med Clin (Barc) 2002;118:78-9. 


\section{BMJ Case Reports}

9. Simeoni S, Puccetti A, Chilosi M, et al. Type 1 neurofibromatosis complicated by pulmonary artery hypertension: a case report. J Med Invest 2007:54:354-8.

10. Engel PJ, Baughman RP, Menon SG, et al. Pulmonary hypertension in neurofibromatosis. Am J Cardiol 2007;99:1177-8.

11. Simonneau G, Robbins IM, Beghetti M, et al. Updated clinical classification of pulmonary hypertension. J Am Coll Cardiol 2009;54:S43-54.

12. Otto CM. Left and right ventricular systolic function. Textbook of clinical echocardiography. Fourth edition. Philadelphia, PA: Saunders Elsevier 2009:125-56.

13. Galiè $\mathbf{N}$, Hoeper MM, Humbert $\mathrm{M}$, et al. Guidelines for the diagnosis and treatment of pulmonary hypertension. The task force for the diagnosis and treatment of pulmonary hypertension of the European society of cardiology (ESC) and the European Respiratory Society (ERS), endorsed by the International Society of Heart and Lung Transplantation (ISHLT). Eur Heart J 2009;30:2493-537.
14. Reynolds RM, Browning GG, Nawroz I, et al. Von Recklinghausen's neurofibromatosis: neurofibromatosis type 1. Lancet 2003;361:1552-4.

15. National Institutes of Health Consensus Development Conference. Neurofibromatosis. Conference statement. Arch Neurol 1988;45:575-8.

16. Friedman JM, Arbiser J, Epstein JA, et al. Cardiovascular disease in neurofibromatosis 1: report of the NF1 cardiovascular task force. Genet Med 2002;4:105-11.

17. Machado RD, Eickelberg 0, Elliott CG, et al. Genetics and genomics of pulmonary arterial hypertension. J Am Coll Cardiol 2009;54(1 Suppl):S32-42.

18. Farber HW, Loscalzo J. Pulmonary arterial hypertension. N Eng/ J Med 2004;351:1655-65

19. Anderson JR, Nawarskas JJ. Pharmacotherapeutic management of pulmonary arterial hypertension. Cardiol Rev 2010;18:148-62.

20. Stringham R, Shah NR. Pulmonary arterial hypertension: an update on diagnosis and treatment. Am Fam Physician 2010;82:370-7.

This pdf has been created automatically from the final edited text and images.

Copyright 2010 BMJ Publishing Group. All rights reserved. For permission to reuse any of this content visit

http://group.bmj.com/group/rights-licensing/permissions.

BMJ Case Report Fellows may re-use this article for personal use and teaching without any further permission.

Please cite this article as follows (you will need to access the article online to obtain the date of publication).

Carrascosa MF, Larroque IC, Rivero J-LG, García J-AS-0, Hoz MC, Ares MA, López XA, Caviedes J-RS. Pulmonary arterial hypertension associated with neurofibromatosis type 1. BMJ Case Reports 2010;10.1136/bcr.05.2010.2961, date of publication

Become a Fellow of BMJ Case Reports today and you can:

- Submit as many cases as you like

Enjoy fast sympathetic peer review and rapid publication of accepted articles

Access all the published articles

Re-use any of the published material for personal use and teaching without further permission

For information on Institutional Fellowships contact consortiasales@bmjgroup.com

Visit casereports.bmj.com for more articles like this and to become a Fellow 